\title{
An Efficient Reaction Process for the Synthesis of Oxazinanes, and Oxazolidines in the Presence of Air
}

\author{
Mohammad Al-Masum*, Baillie W. Lott, Nazanin Ghazialsharif \\ Department of Chemistry, Tennessee State University, Nashville, USA \\ Email: *malmasum@tnstate.edu
}

Received September 4, 2012; revised October 10, 2012; accepted October 19, 2012

\begin{abstract}
After purging air through the mixture of aldehydes and amino alcohols and microwaved the reaction mixture at $50^{\circ} \mathrm{C}$ for minutes gave the corresponding oxazinanes, and oxazolidines in excellent yields.
\end{abstract}

Keywords: Air; Oxazinanes; Oxazolidines; Microwave

Oxazinanes, and oxazolidines are heterocyclic compounds useful anticonvulsant derivatives, and also as ligands for organometallic catalyst. In the literature [1-6], there are some synthetic processes for oxazinanes, and oxazolidines. As for example, a recently published method uses conventional heating system for synthesis of 1 , 3-oxazolidine, by reaction of (2R, 3R)-3-methyl-amino3-phenyl-1,2-propanediol with various aldehydes, in presence of boron trifluoride diethyl etherate as catalyst [7]. In another patent work, Choi and Tatewaki used p-isopropyl-alpha-methyl hydroxyl cinnamic aldehyde and diethanolamine and refluxed in toluene for $2 \mathrm{~h}$ while removing water azeotropically [8]. In this work, we found a very mild condition of microwave irradiated minute reaction and the effect of the air in cyclization process in which nitrogen nucleophiles tethered to oxygen atoms of alcohols easily react with aldehydes for regioselective synthesis of oxazinanes, and oxazolidines (Scheme 1).

This experiment was preformed with the intention to find a milder condition for creating an oxazinane from an aldehyde and N-methyl aminopropanol and oxazolidine from an aldehyde and N-methyl aminoethanol. Several different successful aldehydes and amino alcohols were found that were successful. The results of the experiment show success for the creation of oxazinanes, and oxazolidines by this method.

Initially, the experiment of hydrocinnamaldehyde and $\mathrm{N}$-methyl aminoethanol was run in dry THF under microwave heating. No reaction product was obtained. Same reaction was attempted by using old THF bottle

*Corresponding author. with an assumption that it is exposed in air. A condensation product was found in GC-MS observation. 30 years ago, Eugene Kennedy [9,10] analyzed capillary gas chromatography and reported that formaldehyde in air reacted with N-benzylethanolamine-coated chromosorb 102 sorbent to produce a derivative of formaldehyde, 3-benzyloxazolidine. In another work, Donald Larkin explained the role of catalysts in the air oxidation of aliphatic aldehydes [11]. He has shown metal catalyzed system and non-catalyzed system as well.

Both systems make peracid from aldehyde in the first stage and in the second stage peracid is converted to carboxylic acid. These observations, presumably the freeradical reaction helped us to see the effect of air in oxidation of aldehyde to the corresponding carboxylic acid. The acid then catalyzes the condensation process in microwave within minutes and produces oxazinanes from $\mathrm{N}$-aminopropanol and aldehydes and oxazolidines from aminoalcohols and aldehydes.

To perform the test $1 \mathrm{mmol}$ of the hydrocinnamaldehyde, $2 \mathrm{mmol}$ of the $\mathrm{N}$-methylaminoethanol, and $2 \mathrm{~mL}$ of THF were mixed in a microwave tube. The mixture was then purged with air for 5 minutes and afforded the 3-methyl-2-phenethyl-oxazolidine without further heating. Effect of other common solvents were also examined (Figure 1). In all cases, reaction went smoothly without any heat and choice of solvent had no adverse effect. It is interesting that reaction was actually completed without adding any solvent too (Figure 1, Entry 8). We took advantage of the wide scope of the process and ran all reactions in THF and summarized in Figure 2.

After purging in air for 5 minutes the reaction mixture was run through GC-MS both before and after the mi- 


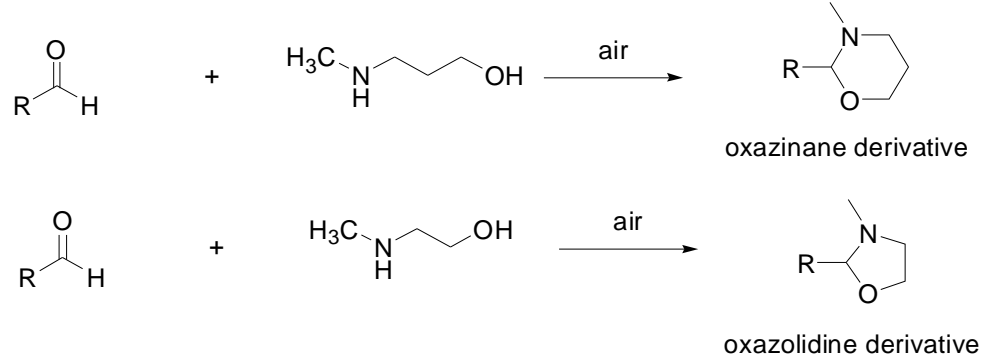

Scheme 1. Regioselective synthesis of oxazinanes, and oxazolidines.

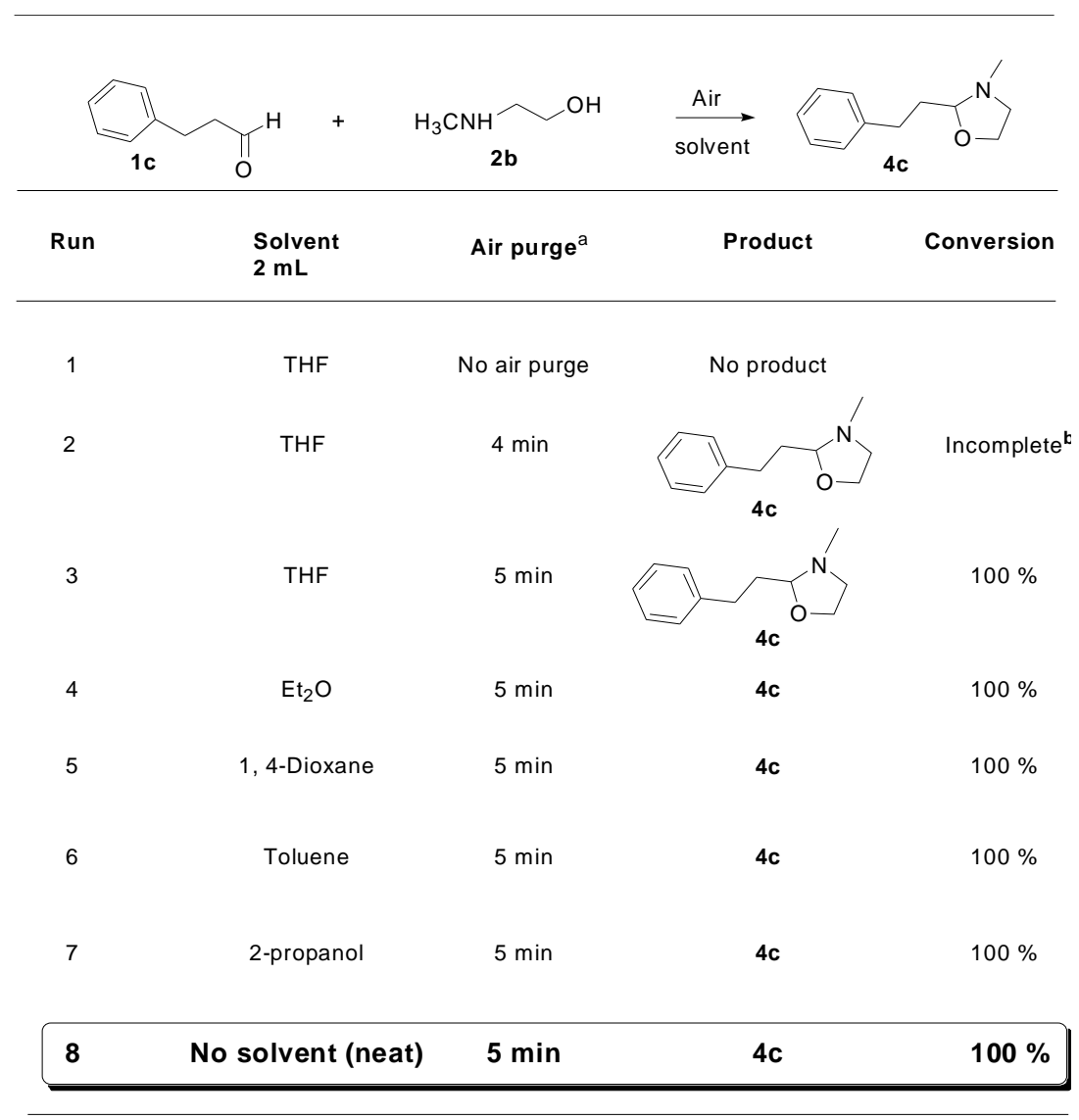

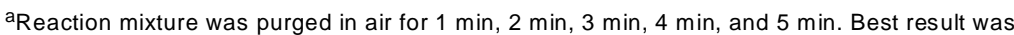
found when the reaction mixture in THF was purged upto 5 minutes. Also $1: 2$ ratio of aldehyde : ethanolamine gave the best result. ${ }^{b}$ trace amount of aldehyde remained.

Figure 1. Solvent effect in air purged oxazolidine synthesis.

crowave. Microwave is used when unreacted starting materials were observed in GC-MS. For oxazinane synthesis, N-methylamino propanol (2a) with aldehydes requires heat to complete the process (Figure 2, Entries 1-4). For oxazolidine case, N-methylaminoethanol (2b) with some aldehydes such as, hydrocinnamaldehyde reaction completed without any heat. The incomplete reactions were microwaved for 30 minutes at $50^{\circ} \mathrm{C}$. Once completed the product was extracted using ethyl acetate and quenched with sodium bicarbonate after which it was dried with anhydrous sodium sulfate. Rotary evaporator was used to evaporate the solvents, and NMR was performed on the product. As noted, some of the aldehydes were found to react almost completely following purging with air. The resulting mixture in microwave reaction tube then heated in microwave system to reach a complete reaction. 3-Phenylbutyraldehyde, hydrocinnamaldehyde, and heptaldehyde all reacted quite fast prior to use of the microwave (Figure 2, Entries 2, 3, and 4 for oxazinanes; Entries 6 and 10 for oxazolidines). Heterocyclic aldehydes such as 2-pyridine carboxaldehyde worked smoothly (Figure 2, Entry 9). Furfuraldehyde 


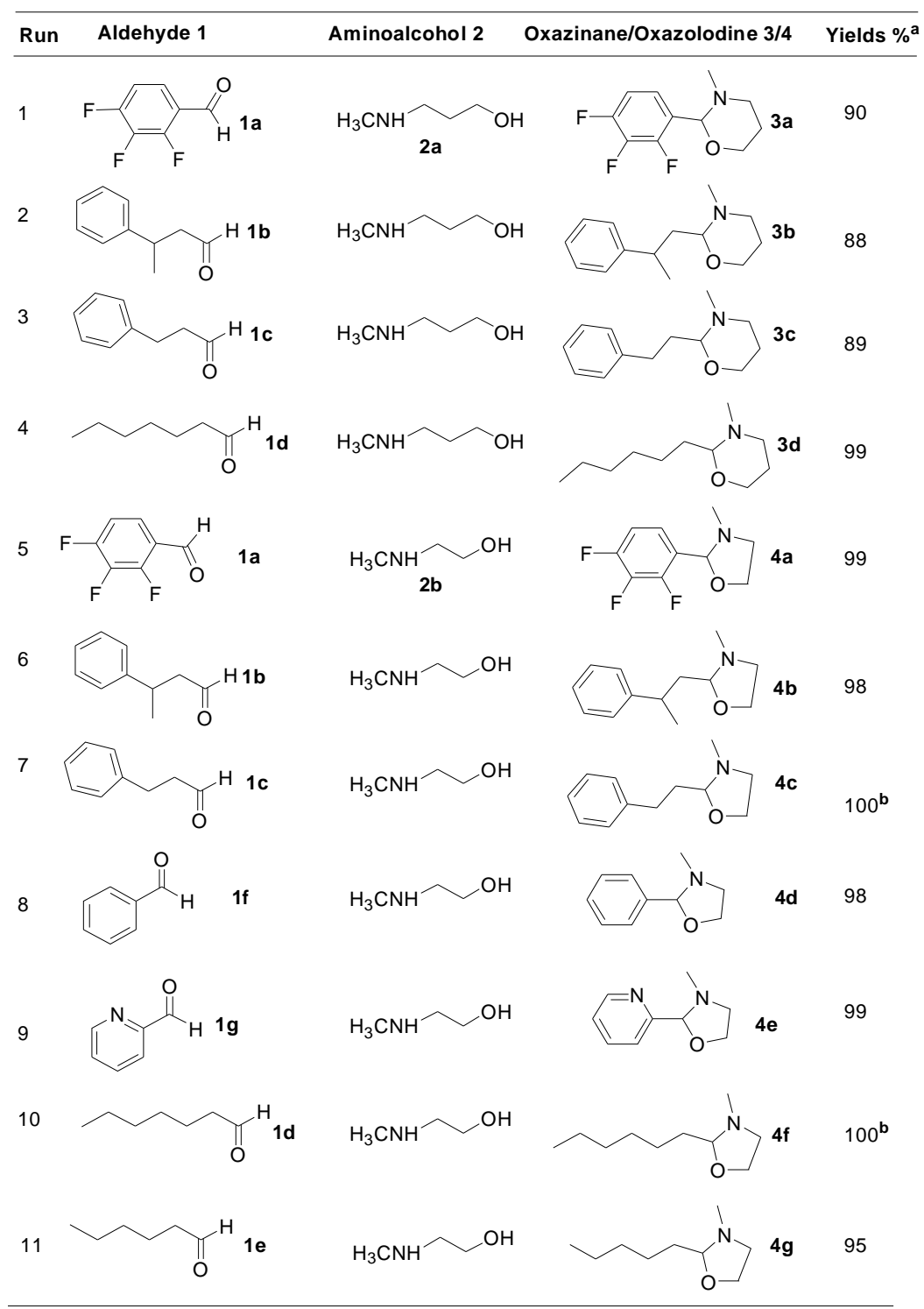

${ }^{a}$ All yields are isolated yields. ${ }^{\mathbf{b}}$ To avoid decomposition the product didn't keep under vacuum for long. High yields may be the presence of trace amount of ethyl acetate.

Figure 2. Synthesis of oxazinanes and oxazolidines.

was also used and it worked well too. There were also two aldehydes that didn't react. These were tiglic aldehyde and pyrenecarboxaldehyde. Two properties of these compounds that could have impeded the reaction were the compact structure of the pyrenecarboxaldehyde and the double bond in tiglic aldehyde. Another important notation is that the reaction does not proceed when aminoethanol is substituted for 2-methylaminoethanol. In order for the reaction to proceed it appears that the nitrogen must be protected to prevent the breakdown of the product. Also, it is observed that if the reaction product is kept in vacuum line under reduced pressure for longer time, the product is decomposed. No condensation product is found when same reaction condition is applied with ketones instead of aldehydes.

In conclusion, it is fascinating that the presence of air forms acid which drives the reaction and microwave heating at $50^{\circ} \mathrm{C}$ for 30 min completes the condensation process by making oxazinanes from the corresponding aldehydes and N-methyl amino propanol. Under same conditions, oxazolidines are formed from the corresponding aldehydes and N-methyl amino ethanol. This system also permits to use wide range of solvents and neat condition as well. The practical application of this new method will interest chemists.

\section{Acknowledgements}

We wish to thank Tennessee State University for finan- 
cial support from US department of education Title III grant.

\section{REFERENCES}

[1] H. Liu, W. Feng, C. W. Kee, D. Leow, W.-T. Loh and C.-H. Tan, "Brønsted Base-Catalyzed Tandem Isomerization-Michael Reactions of Alkynes: Synthesis of Oxacycles and Azacycles," Advanced Synthesis \& Catalysis, Vol. 352, No. 18, 2010, pp. 3373-3379. doi:10.1002/adsc. 201000618

[2] T. Mino, S. Hata, K. Ohtaka, M. Sakamoto and T. Fujita, "Novel Chiral Phosphine-Oxazinane Ligands in Palladium-Catalyzed Asymmetric Allylic Alkylation," Tetrahedron Letters, Vol. 42, No. 29, 2001, pp. 4837-4839. doi:10.1016/S0040-4039(01)00860-7

[3] S. Gandhi, A. Bisai, B. A. Bhanu Prasad and V. K. Singh, "Studies on the Reaction of Aziridines with Nitriles and Carbonyls: Synthesis of Imidazolines and Oxazolidines," The Journal of Organic Chemistry, Vol. 72, No. 6, 2007, pp. 2133-2142. doi:10.1021/jo062564c

[4] A. Joosten, E. Lambert, J.-L. Vasse and J. Szymoniak, "Diastereoselective Access to trans-2-Substituted Cyclopentylamines," Organic Letters, Vol. 12, No. 22, 2010, pp. 5128- 5131. doi:10.1021/ol102038x

[5] N. Srivastava, S. K. Dasgupta and B. K. Banik, "A Remarkable Bismuth Nitrate-Catalyzed Protection of Carbonyl Compounds," Tetrahedron Letters, Vol. 44, No. 6,
2003, pp. 1191-1193. doi:10.1016/S0040-4039(02)02821-6

[6] F. Gosselin, A. Roy, P. D. O'Shea, C. Chen and R. P. Volante, "Oxazolidine Ring Opening and Isomerization to $(E)$-Imines. Asymmetric Synthesis of Aryl- $\alpha$-fluoroalkyl Amino Alcohols," Organic Letters, Vol. 6, No. 4, 2004, pp. 641-644. doi:10.1021/o1036486g

[7] C. Hajji, E. Z. Garcia and J. Sepulveda-Arques, "Synthesis of 1,3-Oxazolidines and 1,3-Dioxalanes by Reaction of (2R, 3R)-3-Methylamino-3-phenyl-1,2-propanediol with Electrophiles," Synthetic Communications, Vol. 33, No. 24, 2010, pp. 4347-4354. doi:10.1081/SCC-120026865

[8] G. Choi and T. Tatewaki, "Jpn Kokai Tokyo Koho," Japanese Patent No. Jp. 2010024286, 2010.

[9] E. R. Kennedy and R. H. Hill Jr., "Determination of Formaldehyde in Air as an Oxazolidine Derivative by Capillary Gas Chromatography," Analytical Chemistry, Vol. 54, No. 11, 1982, pp. 1739-1742. doi:10.1021/ac00248a020

[10] P. A. Smith, C. R. Bowerbank, M. L. Lee, M. Solberg, D. B. Drown, W. Alexander and K. R. Still, "Airborne Aldehydes from Heating Rosin Core Solder and Liquid Rosin Flux to Soldering Temperatures," AIHAJ (A Journal for the Science of Occupational and Environmental Health and Safety), Vol. 61, 2000, pp. 95-101.

[11] D. R. Larkin, "The Role of Catalysts in the Air Oxidation of Aliphatic Aldehydes," The Journal of Organic Chemistry, Vol. 55, No. 5, 1990, pp. 1563-1568. doi: $10.1021 /$ jo00292a035 